\title{
The influence of the scattered field on the reradiation pattern of reflector arrays
}

Appel-Hansen, Jørgen; Larsen, Tove; Kurss, H.; Kahn, W.

Published in:

I E E E Transactions on Antennas and Propagation

Publication date:

1968

Document Version

Publisher's PDF, also known as Version of record

Link back to DTU Orbit

Citation (APA):

Appel-Hansen, J., Larsen, T., Kurss, H., \& Kahn, W. (1968). The influence of the scattered field on the reradiation pattern of reflector arrays. I E E E Transactions on Antennas and Propagation, 16(6), 751-752.

\section{General rights}

Copyright and moral rights for the publications made accessible in the public portal are retained by the authors and/or other copyright owners and it is a condition of accessing publications that users recognise and abide by the legal requirements associated with these rights.

- Users may download and print one copy of any publication from the public portal for the purpose of private study or research.

- You may not further distribute the material or use it for any profit-making activity or commercial gain

- You may freely distribute the URL identifying the publication in the public portal

If you believe that this document breaches copyright please contact us providing details, and we will remove access to the work immediately and investigate your claim. 
antenna temperatures provide checks on the observing conditions. An analog record of radiometer output is also made during the observation, and the measurement quality can also be judged from this record.

All calibration measurements were made with $\tau=4$ seconds, and the routine required a total of 10 minutes from initiation until the results are printed out. The position measurements are completed in the first 7 minutes of the routine.

\section{ACKNOWLEDGMENT}

The authors wish to acknowledge discussions of this problem with J. C. Carter and Mrs. P. P. Crowther. Mrs. Crowther also wrote the program described in the Appendix. The authors also wish to thank H. H. Danforth, H. Hinteregger, and P. R. Schwartz for assistance in the observations.

\section{REFERENCES}

[1] W. Chauvenet, A Manual of Spherical and Practical Astronomy. London: Constable, 1891, ch. 6 and 7.
[2] H. G. Weiss, "The Haystack microwave research facility," IEEE Spectrum, vol. 2, pp. 50-69, Eehruary 1065

[3] W. R. Iliff and J. M. Holt, "Use of surface refractivity in the empirical prediction of total atmospheric refraction," $J$. Research NBS (Radio Propagation), vol. 87D, pp. 31-35, January-February 1963.

[4] W. M. Smart, Combination of Observations. New York: Cambridge, 1958 , ch. 6 .

[5] R. L. Adgie and H. Gent, "Positions of radio sources determined by the interferometer at the Royal Radar Establishment," Nature, vol. 209, pp. 549-551, 1965.

[6] M. Ryle and D. Downes, "High-resolution radio observations of an intense HII region in Cygnus X," Astrophys. $J$., vol. 148, pp. 417-422. 1967.

[7] C. Hazard, M. B. Mackey, and A. J. Shimmins, "Investigation of the radio source $3 \mathrm{C} 273$ by the method of lunar occultations," Nature, vol. 197, pp. 1037-1039, 1963.

[8] T. D. Kinman, J. G. Bolton, R. W. Clarke, and A. Sandage, "Radio and optical data on sixteen quasi-stellar objects," Astrophys.J., vol. 147, pp. 848-850, 1967.

[9] The American Ephemeris and Nautical Almanac for the Year 1967. Washington, D. C.: Government Printing Office, 1965.

[10] J. D. Kraus, Radio Astronomy. New York: McGraw-Hill, 1966, ch. 7.

[11] W. M. Smart, Text-Book on Spherical Astronomy. New York: Cambridge, 1960, ch. 4.

\section{communications}

The Influence of the Scattered Field on the Reradiation Pattern of Reflector Arrays

It is the purpose of this communication to demonstrate that for a passive Van Atta reflector consisting of half-wave dipoles there is not always a maximum of reradiation back in the direction of incidence even when the antenna self-reactances and the mutual impedances are neglected or "tuned out." The need for this demonstration is emphasized by a recent communication by Kurss and Kahn ${ }^{1}$ from which it may be concluded that if the above-mentioned tuning out is made then there is always a maximum of reradiation back in the direction of incidence. That this conclusion is false can readily be seen by

\footnotetext{
Manuscript received March 1, 1968

1 H. Kurss and W. K. Kahn, "A note on reflector arrays," IEEE Trans. Antennas and Propagation (Communications), vol. AP-15, pp. 692-693, September 1967.
}

studying the reradiation patterns of Fig. 5 in Appel-Hansen. ${ }^{2}$ Here, when coupling is neglected, the deviation of some maxima from being back in the direction of incidence is due to the scattering by the antennas.

It should be pointed out that Kurss and Kahn use the term "reradiated field" in a manner different from Larsen" and AppelHansen. ${ }^{2}$ In Kurss and Kahn, the reradiated field means the field due to the interconnection network (including all self- and mutual impedances of the antennas except the radiation resistance), whereas in Larsen and in Appel-Hansen, the reradiated field means the total field, i.e., the sum of the field due to the interconnections between the antennas, the field due to scattering by the antennas, and

2 J. Appel-Hansen, "A Van Atta reflector consisting of half-wave dipoles," IEEE Trans. Antennas and Propagation, vol, AP.14, pp. 694-700, November 1966.

"T. Larsen, "Reflector arrays," IEEE Trans. An tennas and Propagation, vol. AP-14, pp. 689-693, November 1966 the field due to coupling between the antennas.

Kurss and Kahn do mention that there is a scattered field; however, when they set up the condition for retrograde reradiation (their equation (6)], they consider only the field due to the above-mentioned interconnection network and neglect the field due to scattering. It is easily seen from their Fig. 2 that what is there denoted scattered field and reradiated field (patterns with main lobes in the directions shown) may interfere constructively or destructively, especially for angles of incidence near normal. As the field of interest for the application of the Van Atta reflector is the total field, and as the scattered and reradiated fields of their Fig. 2 are of the same order of magnitude for half-wave dipoles, the scattered field should be taken into account in this case.

J. APPEL-Hansen

TOVE LARSEN Lab. of Electromagnetic Theory Technical University of Denmark 2800 Lyngby, Denmark 


\section{Remarks by H. Kurss and}

\section{W. K. Kahn}

Appel-Hansen and Larsen are concerned that readers of our communication ${ }^{1}$ may draw a false conclusion. If they had begun by drawing to the reader's attention that "Kurss and Kahn use the term 'reradiated field' in a manner different from Larsen ${ }^{3}$ and AppelHansen"' they would then have immediately precluded this possibility. When antenna selfreactances and mutual impedances are neglected or tuned out, the conclusion that the reradiated component of field (as defined in our communication) due to the passive Van Atta network interconnection among the antennas has, in general, a maximum back in the direction of incidence is true. When mutual impedances are not tuned out, these may produce shifts in the position of this maximum. Of course, if one defines "reradiated field" as do Appel-Hansen and Larsen, the same words imply a conclusion which is false. Thus the apparent disagreement between Larsen, Appel-Hansen, and ourselves with respect to the performance of an idealized Van Atta array is semantic rather than substantive.

We do not neglect the scattered field. On the contrary, our communication ${ }^{1}$ calls attention to possible interference phenomena among the various component fields. These include not only the reradiated and scattered components, but also the incident component of field as schematized in Fig. 2 of our communication.1 (The term "total field" employed by Appel-Hansen and Larsen is somewhat inappropriate as it ignores the incident field also present and thus should, perhaps, be replaced by "total radiated field." This latter terminology is employed, for example, in Bauer. ${ }^{5}$

The case in which a reradiated lobe is directed parallel to a lobe scattered in reception, is mentioned explicitly in the fourth paragraph of our communication. ${ }^{1}$ These two field components interfere, canceling one another completely when an open circuit is placed at each antenna port. ${ }^{6}$ This happens in a passive Van Atta array at normal incidence, when the equivalent line lengths in the Van Atta network are an integral number of wavelengths long.

Appel-Hansen and Larsen suggest the question of whether one can force the retrograde condition on the total radiated field rather than on the reradiated component (our usage) alone. This question was answered in our communication, ${ }^{1}$ where it was shown that this is possible if and only if active interconnections are allowed.

H. KuRss Dept. of Math. Adelphi University Garden City, N. Y.

W. K. KAHN ${ }^{\top}$ Dept. of Electrophysics Polytechnic Institute of Brooklyn Brooklyn, N. Y.

4anuscript received May 31, 1968

b. H. Bauer, "Technique for amplitude modulating a Van Atta radar reflector," Proc. IRE (Correspondence), vol. 49, pp. 634-635, March 1961.

6 W. K. Kahn and H. Kurss, "Minimum-scattering antennas," IEEE Trans. Antennas and Propagation, vol. AP-13, pp. 671-675, September 1965.

i Presently on leave at the Branch Office of the Office of Naval Research, London, England.

\section{A Log-Periodic Antenna with Vertically Polarized Omnidirectional Radiation}

Abstract-This communication reports the results of an experimental investigation of a new log-periodic (LP) antenna. The antenna consists of an LP array of radial waveguides excited by a two-wire transmission line. The antenna exhibits a vertically polarized omnidirectional radiation pattern which is essentially constant over the designed bandwidth.

Much progress has been made in the development of frequency-independent antennas. The main features of this class of antennas are directional radiation patterns and impedance which are constant over a very wide bandwidth. These antennas are generally not capable of omnidirectional operation. Dyson [1] has shown that a logspiral antenna of the proper configuration would have an approximately omnidirectional radiation pattern which is circularly polatized. The discone antenna, which does not belong to the log-periodic (LP) class, has an omnidirectional vertically polarized radiation pattern over an approximate 6 to 1 bandwidth [2], [3]. The purpose of this investigation was to determine whether the log-periodic principle could be applied to a structure to give omnidirectional and vertically polarized characteristics over a wider range of frequencies than is now possible.

The basic element chosen for such a structure was a pair of parallel circular disks which are closely spaced compared to the wavelength. Such a basic element, when excited at the center of the plates, operates as a radial waveguide in the lowest $E$-type mode [4], thus producing the desired far-field radiation patterns. The LP structure is composed of an array of such disks with the diameter of the plates and the spacing between them varying in a log-periodic manner. The elements are alternately connected to a narrow two-wire transmission line running through the center of the disks. The LP antenna is shown in Fig. 1.

Tests were made on three models of the structure having values of the LP parameter $\tau$ of $0.90,0.96$ and 0.98 . The ratio of the plate spacing to the diameter $\sigma$ was held constant at 0.115 . The antennas were designed to operate over a 3:1 bandwidth ( $500 \mathrm{MHz}$ to $1500 \mathrm{MHz}$ ). The diameter of the largest plate was approximately 0.4 wavelength and the height was approximately 0.93 wavelength at $500 \mathrm{MHz}(\tau=0.96)$. Measurements of impedance, far-field radiation patterns, and polarization were made.

For all models, the impedance was relatively constant over the designed frequency quency range, being within an SWR of 2:1 relative to $15+j 20$ ohms. The far-field pattern measurements showed that the structure was omnidirectional within $3 \mathrm{~dB}$ over most of the designed bandwidth. Better omnidirectionality was obtained with $\tau$ closer to 1 than when $\tau$ was a lower value. Fig. 2(a) shows the typical azimuth variation. The ele-

Manuscript received March 13, 1968; revised Apri 1, 1968 and July 8, 1968. This work was supported in part by the Small Industries Research Program through The Pennsylvania State University, and in part by $\mathrm{Na}$ tional Science Foundation Traineeship Grant GE7919.1.

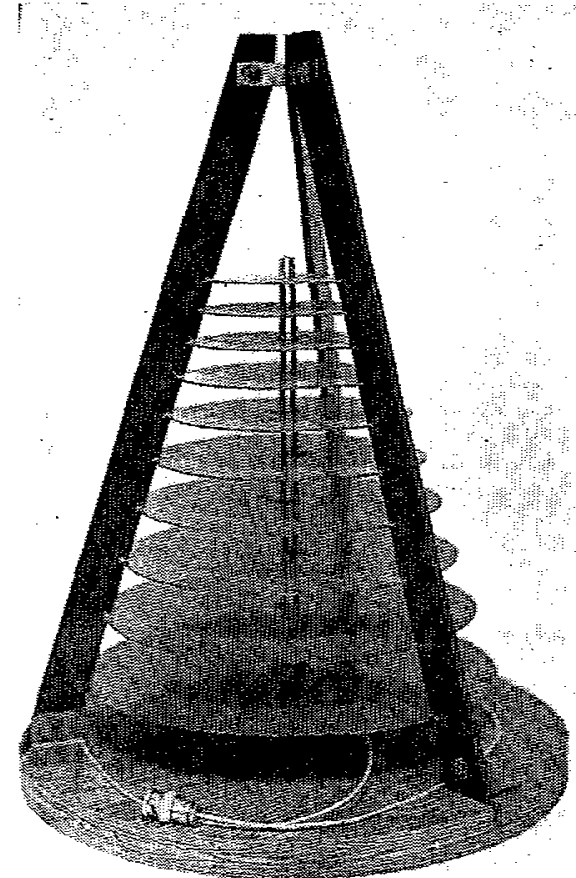

Fig. 1. The log-periodic parallel plate antenna.

vation patterns showed that the angle of maximum radiation occurred between 45 to 75 degrees with the axis of the antenna and scans with frequency. A typical elevation pattern is shown in Fig. 2(b). The polarization measurement, shown in Fig. 2(c), was made by changing the orientation of a linearly polarized transmitting antenna with respect to the axis of the test antenna. Zero degrees on Fig. 2(c) represents the point where the polarization of the transmitted wave was parallel to the axis of the test antenna, i.e., vertically polarized. Ninety degrees represents the point where the polarization of the transmitted wave was perpendicular to the axis of the test antenna, i.e., horizontal polarization. Thus the structure is, indeed, vertically polarized. More details of the experimental investigation may be found in [5].

The investigation indicated that the structure is capable of vertically polarized omnidirectional radiation and an impedance characteristic which are both relatively constant over a very wide bandwidth. However, the deviations from the desired omnidirectional characteristics indicate that the lowest $E$-type mode may not be the dominant one on the antenna at some frequencies. Near-field measurements indicate that higher-order modes are present. The nonpropagating modes will not affect the far-field radiation characteristics, but can account for the large reactive component of the input impedance.

A comparison of the LP disk antenna with a discone antenna of the same bandwidth (3 to 1) indicates that the LP antenna is considerably larger in size. For a lower cutoff frequency of $500 \mathrm{MHz}$, the largest diameter of the $L P$ antenna is 9 inches whereas the largest diameter of the discone antenna is 5.5 inches. The height of the LP antenna is 20 inches compared to 5 inches for the discone antenna. Theoretically, the LP disk antenna should be capable of operation over a wider bandwidth than is obtainable with a discone antenna. 